\title{
THERMAL AND ELECTRICAL BEHAVIOUR OF THE SUPERPROTONIC CONDUCTOR PHASE IN Rb $2\left(\mathrm{HSeO}_{4}\right)_{1.5}\left(\mathrm{H}_{2} \mathrm{AsO}_{4}\right)_{0.5}$
}

\author{
Noura NOUIRI, Khaled JAOUADI*, Tahar MHIRI, Nabil ZOUARI
}

Laboratoire physico-chimie de l'état solide, Faculté des Sciences de Sfax, BP 1171, 3038 Sfax, Tunisie

$$
\text { nouirinoura@yahoo.fr }
$$

Laboratoire physico-chimie de l'état solide, Faculté des Sciences de Sfax, BP 1171, 3038 Sfax, Tunisie

$$
\text { khaledjaouadi@yahoo.fr }
$$

Laboratoire physico-chimie de l'état solide, Faculté des Sciences de Sfax, BP 1171, 3038 Sfax, Tunisie

$$
\text { taharmhiri@yahoo.fr }
$$

Laboratoire physico-chimie de l'état solide, Faculté des Sciences de Sfax, BP 1171, 3038 Sfax, Tunisie

\section{bizrirl@yahoo.fr}

\begin{abstract}
Crystals of a new compound with a superprotonic phase transition $\mathrm{Rb}_{2}\left(\mathrm{HSeO}_{4}\right)_{1.5}\left(\mathrm{H}_{2} \mathrm{AsO}_{4}\right)_{0.5}$ (noted $\mathrm{RbHSeAs}$ ), were synthesized by slow evaporation of an aqueous solution at room temperature. The differential scanning calorimetric analyses showed two endothermic peaks at $465 \mathrm{~K}$ and $566 \mathrm{~K}$. The last peak corresponds to the decomposition of the material. The first transition was characterized by several techniques (impedance spectroscopy, complex modulus, Raman and X-ray diffraction powder depending on temperature). ac impedance measurements revealed that, upon heating, the compound undergoes at $\sim 443 \mathrm{~K}$ a sharp increase in conductivity from a low temperature protonic phase to a superprotonic conductivity phase. The activation energies calculated from the modulus $\left(\Delta \mathrm{E}_{\mathrm{f}}\right)$ and impedance $\left(\Delta \mathrm{E}_{\sigma}\right)$ spectra respectively are approximately equal, suggesting that the transport properties in this material above and below the superprotonic phase transition $(443 \mathrm{~K})$ are probably due to an $\mathrm{H}^{+}$protons hopping mechanism.
\end{abstract}

\section{Indexing terms/Keywords}

Inorganic materials; $\mathrm{Rb}_{2}\left(\mathrm{HSeO}_{4}\right)_{1.5}\left(\mathrm{H}_{2} \mathrm{AsO}_{4}\right)_{0.5}$; Thermal behavior; Raman spectroscopy; Superprotonic phase transition

\section{Council for Innovative Research}

Peer Review Research Publishing System

Journal: Journal of Advances in Chemistry

Vol.10, No.7
editorjaconline@gmail.com 


\section{INTRODUCTION}

The compounds of the general formula $\mathrm{M}_{2}\left(\mathrm{HXO}_{4}\right)_{(2-x)}\left(\mathrm{H}_{2} \mathrm{AO}_{4}\right)_{\mathrm{x}}$, where $(\mathrm{M}=\mathrm{K}, \mathrm{Rb}$ and $\mathrm{Cs}$; $\mathrm{X}=\mathrm{S}$, Se and $A=P, A s)$ are of interest because their high-temperature phase exhibits an unusually high conductivity ranging from $7 \times 10^{-4}$ to $37 \times 10^{-3} \Omega^{-1} \mathrm{~cm}^{-1}[1-8]$. Hence they belong to the family of superionic-protonic conductors, which are of great interest because of their potential use in various electrochemical devices such as batteries, fuel cells, electrochemical sensors and electrochemical reactors [9-12]. The most interesting result was obtained for the title compound because its superconducting transition temperature is lowered to $443 \mathrm{~K}$

In our previous work, we have studied the superprotonic transport and relaxation properties and we describe the thermal behaviour by differential scanning calorimetric and thermo-gravimetric analyses of the rubidium selenate-arsenate solid acid family $\mathrm{Rb}_{2}\left(\mathrm{HSeO}_{4}\right)_{1.5}\left(\mathrm{H}_{2} \mathrm{AsO}_{4}\right)$. Accordingly, a detailed analysis of the frequency and temperature dependence of the ac conductivity data is necessary in order to characterize the microscopic mechanisms and the accompanying relaxation phenomena of the charge carrier transport.

\section{EXPERIMENTAL}

\subsection{Crystal growth}

Crystals of $\mathrm{RbHSeAs}$ were grown from aqueous solutions containing rubidium carbonate $\mathrm{Rb}_{2} \mathrm{CO}_{3}$, selenic acid $\mathrm{H}_{2} \mathrm{SeO}_{4}$ and arsenic acid $\mathrm{H}_{3} \mathrm{AsO}_{4}$ in molar ratio (Rb:Se:As = 4:3:1), as reported earlier [13], according to the following reaction:

$$
2 \mathrm{Rb}_{2} \mathrm{CO}_{3}+3 \mathrm{H}_{2} \mathrm{SeO}_{4}+\mathrm{H}_{3} \mathrm{AsO}_{4} \longrightarrow 2 \mathrm{Rb}_{2}\left(\mathrm{HSeO}_{4}\right)_{1.5}\left(\mathrm{H}_{2} \mathrm{AsO}_{4}\right)_{0.5}+2 \mathrm{H}_{2} \mathrm{O}+2 \mathrm{CO}_{2}
$$

Slow evaporation of water under ambient conditions yielded transparent and colorless single crystals of $\mathrm{Rb}_{2}\left(\mathrm{HSeO}_{4}\right)_{1.5}\left(\mathrm{H}_{2} \mathrm{AsO}_{4}\right)_{0.5}$. The formula of this material was determined by chemical analysis and confirmed by structural refinement [13].

\subsection{Thermal behavior}

The differential scanning calorimetry analysis was performed with a METTLER DSC131 instrument for temperatures ranging from 298 to $673 \mathrm{~K}$ with a heating rate of $5 \mathrm{~K} \cdot \mathrm{min}^{-1}$. A polycrystalline sample of $34.72 \mathrm{mg}$ was placed in hermetic aluminum cell in nitrogen atmosphere.

Thermo-gravimetric measurements were performed with a SETARAM (TG-ATD 92) thermo flex instrument under flowing air, with a heating rate of $5 \mathrm{~K} \cdot \mathrm{min}^{-1}$ from 298 to $673 \mathrm{~K}$. A powdered sample, $57.28 \mathrm{mg}$, was spread evenly in a large platinum crucible to avoid mass effects.

Temperature-dependent X-ray powder diffraction (TDXD) was performed with a powder diffractometer combining the curved-position-sensitive detector (CPS120) from INEL and a high temperature attachment from Rigaku. The detector was used in a semi-focusing arrangement by reflection (Cu Ka1 radiation, $\lambda=1.5406 \AA$ ) as described elsewhere [14].

\subsection{Impedance measurements}

The analysis of the frequency response of ac conductivity data was used to determine the superprotonic behaviour of $\mathrm{Rb}_{2}\left(\mathrm{HSeO}_{4}\right)_{1.5}\left(\mathrm{H}_{2} \mathrm{AsO}_{4}\right)_{0.5}$. Complex impedance measurements were performed using a compressed pellet of $\sim 8 \mathrm{~mm}$ diameter and $0.5 \mathrm{~mm}$ thickness sintered at $298 \mathrm{~K}$. Silver paint was evenly applied on both sides of the pellet for better electrical contact, the sample was then held between two spring-loaded electrodes. The electrical properties were collected under stagnant air atmosphere and determined by impedance and modulus method using a frequency response analyser (Hewlett - Packard 4192 A LF). The impedance $\left|Z^{*}\right|$ and phase angle $\theta$ were measured with a computer interfaced. The frequency range was $100 \mathrm{~Hz}-13 \mathrm{MHz}$ and measurements were carried out at constant temperature ranging from $295 \mathrm{~K}$ to $503 \mathrm{~K}$ and maintained at $\pm 1 \mathrm{~K}$ accuracy by a Herrmann - Moritz 28480 controller for half an hour before collecting data.

\subsection{Raman spectroscopy}

Raman spectra of the crystals selected in a cell were obtained in the range $300-523 \mathrm{~K}$ on a computerized RTI 30 Dilor triple monochromator. The $514 \mathrm{~nm}$ radiation from a spectra-physics model 2000 argon ion laser was used for excitation with a powder between 0.1 and $0.2 \mathrm{~W}$. A home-built furnace was employed for high-temperature experiments. The resolution of the spectrometer was between 0.5 and $2 \mathrm{~cm}^{-1}$ and the accuracy of the temperature measurements was about $2 \mathrm{~K}$.

\section{RESULTS AND DISCUSSION}

\subsection{Structural properties}

The structural properties [13] of the crystals were characterized by $X$-ray single analysis (performed at room temperature), which revealed that (RbHSeAs) crystallizes in space group $P-1$ with lattice parameters: $a=7.6950(5) \hat{A}$, $b=7.9317(5) \hat{A}, c=8.0392(4) \hat{A}, \alpha=70.249(4)^{\circ}, \beta=87.851(4)^{\circ}$ and $\gamma=86.622(4)^{\circ}$. This compound has a unit cell volume $460.92(7) \AA^{3}$ and two formula units per cell, giving a calculated density of 3.302 . The structure was solved from 3519 independent reflections and refined with 110 parameters yielded weighted residuals of 0.0898 and 0.0502 based on $\mathrm{F}^{2}$ and $\mathrm{F}$ values, respectively. The crystal structure of (RbHSeAs) projected onto the bc plane is shown in Fig. 1. This 
structure is characterized by $\mathrm{HSeO}_{4}{ }^{-}$and disordered $\left(\mathrm{H}_{x} \mathrm{Se} / \mathrm{As}\right) \mathrm{O}_{4}{ }^{-}$tetrahedra connected to dimmer via hydrogen bridges. These dimmers are linked and stabilized by an additional hydrogen bonds $(\mathrm{O}-\mathrm{H}-\mathrm{O})$ and hydrogen bonds $(\mathrm{O}-\mathrm{H} \cdots \mathrm{O})$ to built a chains of dimmers, which are parallel to the $\left[\begin{array}{lll}0 & 1 & 0\end{array}\right]$ direction Fig. 1 . The rubidium atoms have a nine fold coordination.



Figure 1: Projection of $\mathrm{Rb}_{2}\left(\mathrm{HSeO}_{4}\right)_{1.5}\left(\mathrm{H}_{2} \mathrm{AsO}_{4}\right)_{0.5}$ crystal structure along the a axis

\subsection{Calorimetric and thermo-gravimetric analyses}

The results of the high-temperature behavior of (RbHSeAs) are presented in Fig.2. The differential scanning calorimetric (DSC) revealed that (RbHSeAs) undergoes structural changes over the temperature $465 \mathrm{~K}$ which are unrelated to decomposition; its weight showed by the thermo-gravimetric curve (TGA) is stable to $480 \mathrm{~K}$. This endothermic peak was also characterized by impedance and modulus measurements and was attributed to the superprotonic phase transition of (RbHSeAs) materials. The high-temperature phase of $\mathrm{Rb}_{2}\left(\mathrm{HSeO}_{4}\right)_{1.5}\left(\mathrm{H}_{2} \mathrm{AsO}_{4}\right)_{0.5}$ is thus 'superprotonic' in nature .

The decomposition of (RbHSeAs) occurs in two stages, Fig. 2. The first and the second weight loss regions occur over the temperature ranges $510-545 \mathrm{~K}$ and $570-650 \mathrm{~K}$, respectively. Approximately $5 \%$ of the mass is lost, which corresponds to 1.25 molecules of water per formula unit or complete dehydration. Those two weight losses are accompanied by one endothermic peak in the DSC curve at $566 \mathrm{~K}$.

In order to get further information about the first phase transition revealed by the differential scanning calorimetric (DSC), we have undertaken X-ray powder diffraction, performed as a function temperature at $\mathrm{T}=298 \mathrm{~K}, \mathrm{~T}=473 \mathrm{~K}$ and $\mathrm{T}=503 \mathrm{~K}$ (Fig. 3). We select the $\theta$ interval which shows significant changes with temperature variation. The results shown in Fig. 3, demonstrate that the compound $\mathrm{Rb}_{2}\left(\mathrm{HSeO}_{4}\right)_{1.5}\left(\mathrm{H}_{2} \mathrm{AsO}_{4}\right)_{0.5}$ reveal a structural transition upon heating to $473 \mathrm{~K}$. Indeed, upon heating the samples from 298 to $473 \mathrm{~K}$, the X-ray powder show the appearance of some reflections and the disappearance of others indicating sever changes in structure. This confirms the first transition observed at $\mathrm{T}=465 \mathrm{~K}$ by 
the DSC which is attributed to the superprotonic phase transition. The third powder diffractogram (at $\mathrm{T}=503 \mathrm{~K}$ ) contains the same reflections observed in that at $\mathrm{T}=473 \mathrm{~K}$, indicates that the title compound takes place at much higher temperatures, with an onset of approximately $510 \mathrm{~K}$.

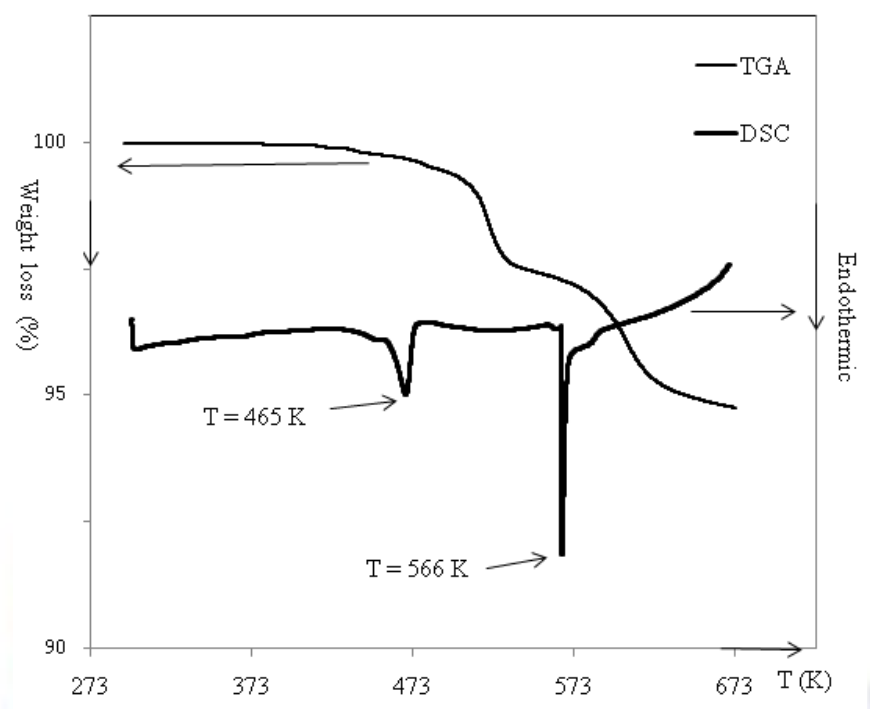

Figure 2: The differential scanning calorimetry (DSC) and the thermogravimetry (TG) of $R b_{2}\left(\mathrm{HSeO}_{4}\right)_{1.5}\left(\mathrm{H}_{2} \mathrm{AsO}_{4}\right)_{0.5}$

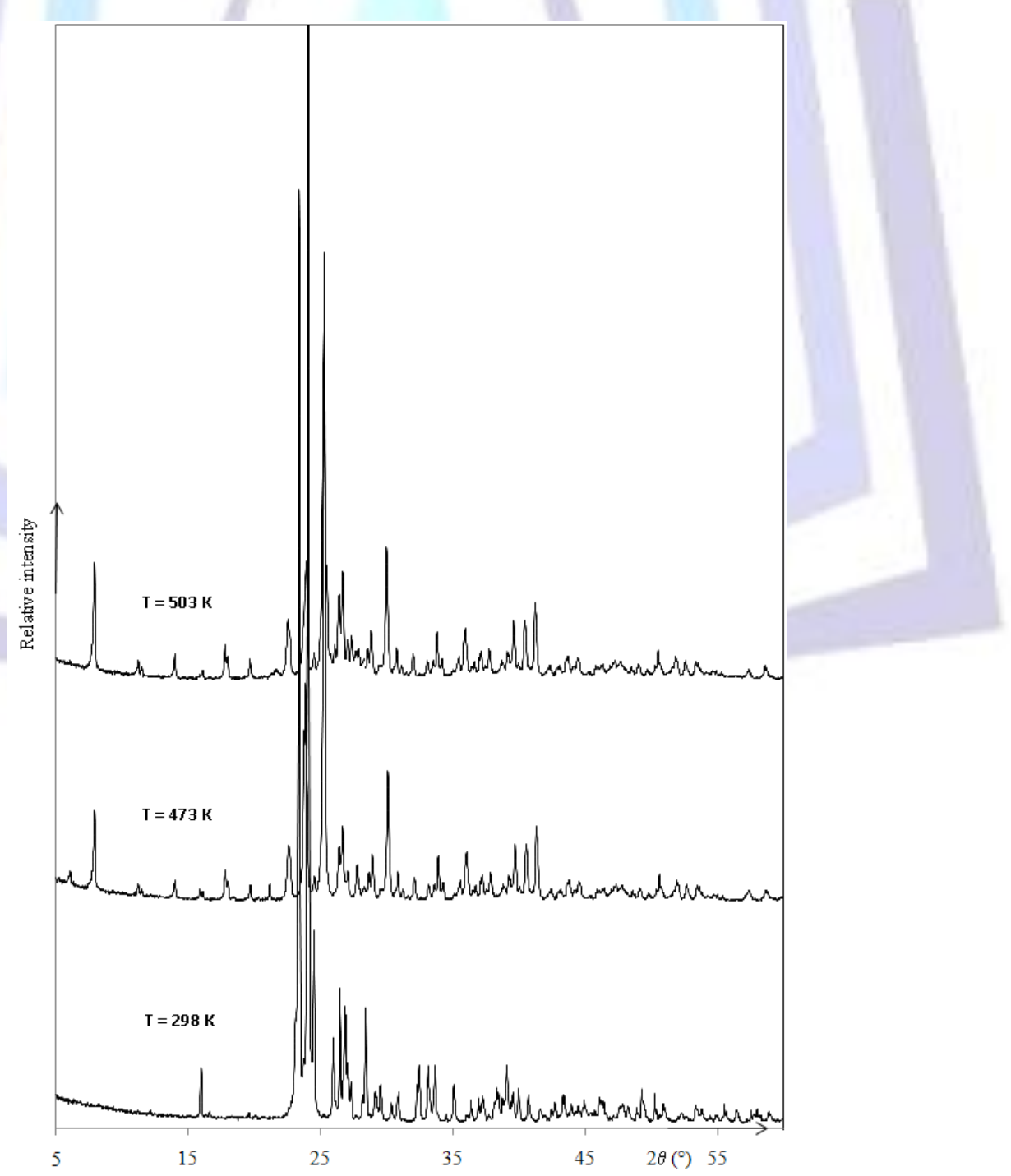

Figure 3: Evolution of X-ray powder diffraction at various temperatures for $\mathbf{R b}_{2}\left(\mathrm{HSeO}_{4}\right)_{1.5}\left(\mathrm{H}_{2} \mathrm{AsO}_{4}\right)_{0.5}$ 


\section{3. ac conductivity behavior}

Four different formalisms are generally employed for analyzing the ac response of materials namely: the complex dielectric constant $\varepsilon^{*}$, complex electric modulus $\mathrm{M}^{*}$, complex impedance $\mathrm{Z}^{*}$ and complex admittance $\mathrm{G}^{*}$. We have used the $\mathrm{Z}^{*}, \varepsilon^{*}$ and $\mathrm{M}^{*}$ representations to analyse the conductivity behaviour.

The ionic conductors (ICs) with point defects lead to a conductivity ranging up to $10^{-5} \Omega^{-1} \mathrm{~cm}^{-1}$ whereas the superionic conductors (SICs) result in a conductivity of at least $10^{-4} \Omega^{-1} \mathrm{~cm}^{-1}$. The main difference between these two groups of materials concerns the activation energy $\left(\Delta \mathrm{E}_{\sigma}\right)$ : in the case of SICs, $\Delta \mathrm{E}_{\sigma}$ is lower than $0.4 \mathrm{eV}$ while in ICs, values varying between 0.6 and $1.2 \mathrm{eV}$ are usually observed [15]. The superionic conductors have thus a high conductivity far below the melting point. This fundamental difference is due principally to the particular structures of SICs.

Temperature dependence of the protonic conductivity of (RbHSeAs) was determined from the analysis of the impedance spectroscopy at different temperatures. Complex plane plots of the complex impedance diagrams, - Z" versus $Z^{\prime}$, at selected temperatures are shown in Fig. 4(a and b) in phases low and high temperatures, respectively. These impedance spectra show one non-ideal semicircle arc, which was attributed to the bulk boundary properties and whose center is displaced below the real axis. This shows that (RbHSeAs) follows the Cole-Cole law and their extrapolation gives rise to an $[\alpha(\pi / 2)$ ] dispersion angle where $\alpha=0.133$ is an empirical parameter $(0 \leq \alpha \leq 1)$ proportional to the degree of deviation from the Debye model. The bulk ohmic resistance relative to each experimental temperature is the intercept on the real axis of the zero-phase angle extrapolation of the highest-frequency curve. The observed non-ideal semicircle was modeled using an equivalent circuit that contains one sub-circuit which consists of a resistance $\mathrm{Rg}$, a capacitance $\mathrm{Cg}$ and a constant phase element (CPE) connected in parallel which represents the grain response of the sample. These curves also show the temperature dependence of the resistance proving the superprotonic conduction properties of (RbHSeAs).

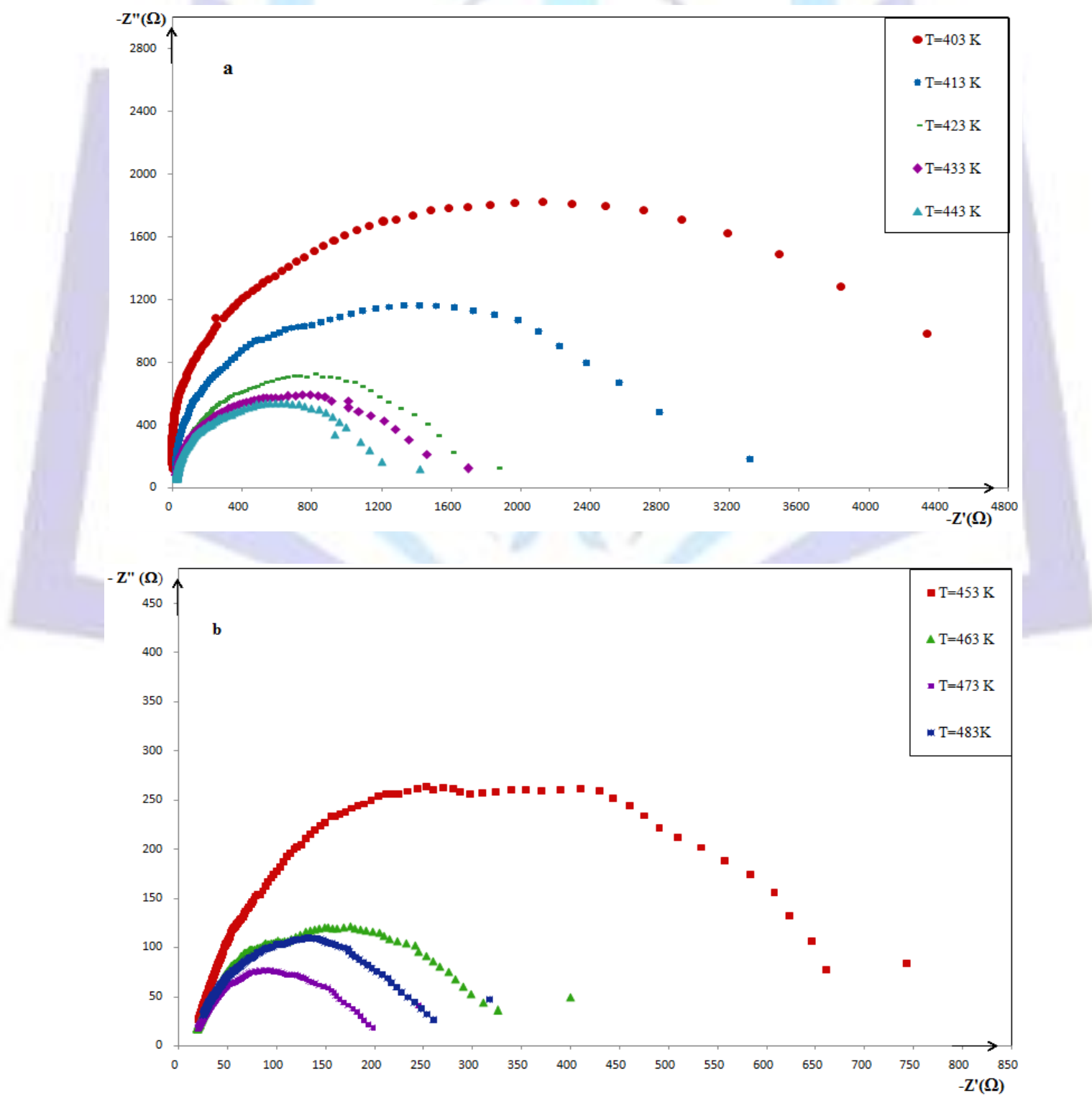

Figure 4(a,b): Complex impedance diagrams - Z" versus $\mathrm{Z}^{\prime}$ for $\mathrm{Rb}_{2}\left(\mathrm{HSeO}_{4}\right)_{1.5}\left(\mathrm{H}_{2} \mathrm{As} \mathrm{O}_{4}\right)_{0.5}$ at various temperatures 
The temperature dependence of the conductivity between 333 and $503 \mathrm{~K}$ is represented in Fig. 5 , in a $\log (\sigma \mathrm{T})$ vs $1000 / \mathrm{T}$ plot. Below $443 \mathrm{~K}$, the protonic conductivity can be described well by the Arrhenius relation: $\sigma \mathrm{T}=\sigma_{0} \exp \left(-\Delta \mathrm{E}_{\sigma} / \mathrm{kT}\right)$ (1) with an activation energy $\Delta \mathrm{E}_{\sigma}=0.54 \mathrm{eV}$, where $\sigma_{0}$ is the pre-exponential factor, $\Delta \mathrm{E}_{\sigma}$ is the activation energy for ion migration and $\mathrm{k}$ is Boltzmann's constant. At the temperature $443 \mathrm{~K}$, the conductivity jumped from $1.52 \times 10^{-4} \Omega^{-1} \mathrm{~cm}^{-1}$ to $0.87 \times 10^{-3} \Omega^{-1} \mathrm{~cm}^{-1}$ at $473 \mathrm{~K}$, characterizing the superprotonic conduction phase of the salt. The activation energy decreases from $0.54 \mathrm{eV}$ at low temperature to $0.32 \mathrm{eV}$ in the superionic phase, also such behavior shows the superprotonic conduction of $\mathrm{Rb}_{2}\left(\mathrm{HSeO}_{4}\right)_{1.5}\left(\mathrm{H}_{2} \mathrm{AsO}_{4}\right)_{0.5}$ compound [15]. The transition observed at $443 \mathrm{~K}$, corresponds to the structural transformation between the triclinic phase and the superprotonic phase. Therefore, this transition which revealed by thermo-differential measurement, is well related to the hydrogen bonds in which the proton moves between the potential wells. Thus, the superionic phase transition corresponds to the melting of the proton sublatttice reaching the 'quasi-liquid' state where protons of the $\mathrm{SeO}_{4}{ }^{-2}$ and $\mathrm{AsO}_{4}{ }^{-3}$ tetrahedral ions contribute to the unusually high conductivity as in the case of $\mathrm{CsHSO}_{4}$ [16]. This behavior is characteristic of a plastic phase and implies a 'free' rotation of $\mathrm{HSeO}_{4}$ ions on given sites. In the superionic phase a 'quasi-liquid' state is manifested and both protons and rubidium ions are disordered while in low temperature, the disorder is essentially confined to the protons. The drastic increase in conductivity by almost ten orders of magnitude on going from $443 \mathrm{~K}$ to $473 \mathrm{~K}$, is thus related to the high disorder of both sublattices.

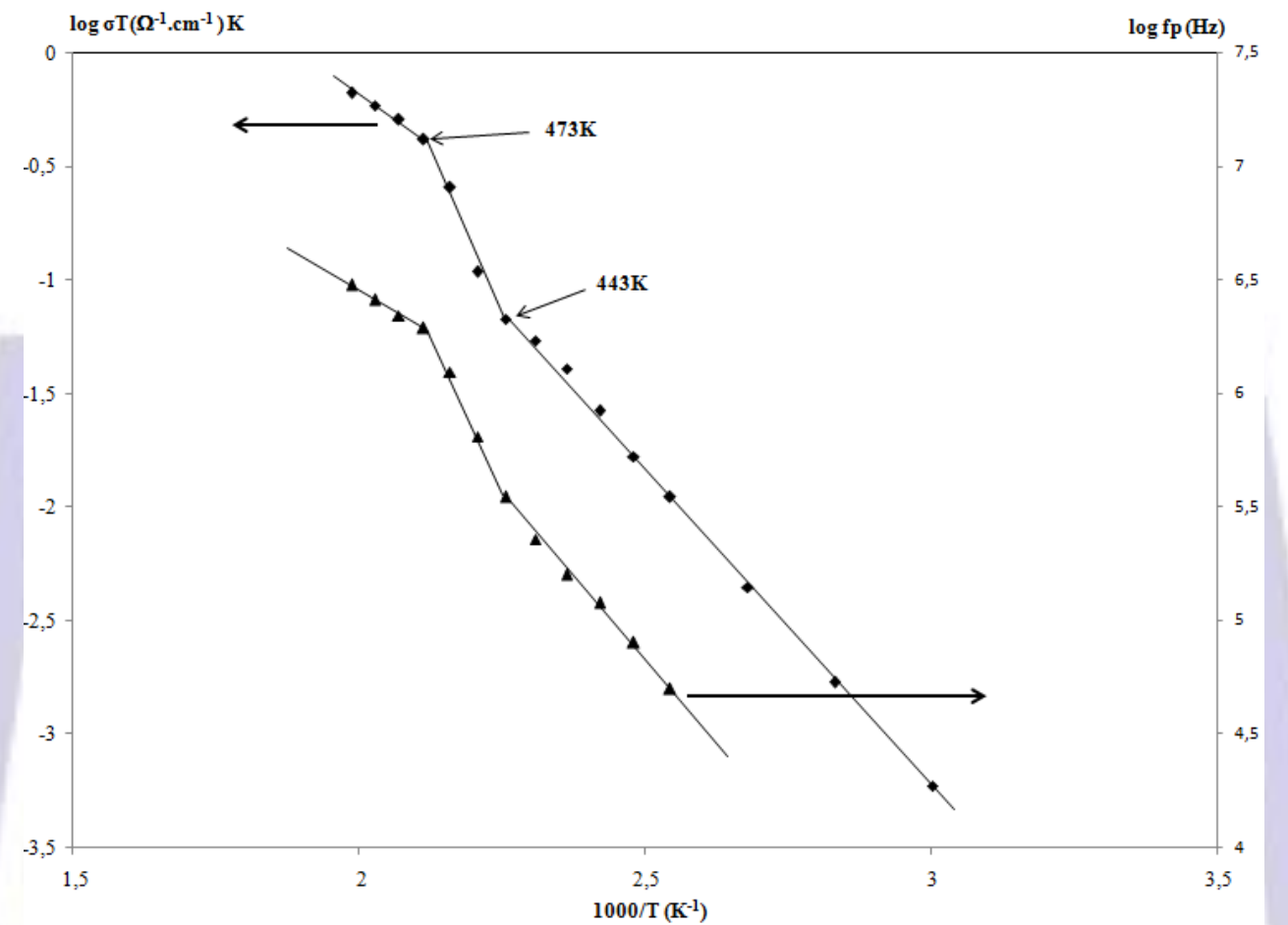

Figue 5: Temperature dependences of $\log (\sigma T)=f\left(10^{3} / T\right)$ and $\log f p=f\left(10^{3} / T\right)$, where $f p$ is the M"max peak frequency, for $\mathrm{Rb}_{2}\left(\mathrm{HSeO}_{4}\right)_{1.5}\left(\mathrm{H}_{2} \mathrm{AsO}_{4}\right)_{0.5}$

An analysis of the ion conductivity relaxation process in (RbHSeAs) has been undertaken in the complex electric modulus formalism, $\left(M^{*}=M^{\prime}+j M^{\prime \prime}(2)\right)$. This formalism is useful in determining the charge carrier parameters such as the conductivity relaxation time [17]. For a temperature and a frequency given, the real part, $\mathrm{M}^{\prime}$, and the imaginary part, $\mathrm{M}$ ", of the $\mathrm{M}^{*}$ complex modulus have been calculated from the complex impedance data $\left(Z^{*}=Z^{\prime}-j Z^{\prime \prime}(3)\right)$ by the following relations: $M^{\prime}=\omega C_{0} Z^{\prime \prime}(4)$ and $M^{\prime \prime}=\omega C_{0} Z^{\prime}(5)$. Isothermal frequency spectra, during heating process of the real, log $M^{\prime}$ and the normalized M"/M"max imaginary part of the electric modulus for (RbHSeAs) versus log f are displayed in Fig. 6 and Fig. 7, respectively. It is noticed that for all temperatures given, the real modulus $M$ ' tends to a frequency-independent constant M' $\infty$ at high frequencies. At low frequencies, it decreases sharply (Fig. 6), which indicates that the electrode polarization phenomena make a negligible contribution to $\mathrm{M}^{*}$ and may be ignored when the electric data are analysed in this form [17].

The M"/M"max spectrum relative to a given temperature shows an asymmetrical peak approximatively centered in the dispersion region of $\mathrm{M}^{\prime}$ (Fig 7). The region to the left of the peak is where the $\mathrm{H}^{+}$protons are mobile over long distances whereas the region to the right is where the ions are spatially confined to their potential wells. It is clear from this figure that the maximum of the asymmetric peak shifts toward higher frequencies as the temperature is increased. The frequency range where the peak occurs is indicative of the transition from long-range to short-range mobility at increasing frequency and is defined by the condition $\omega \tau_{\sigma} \approx 1$ where $\tau_{\sigma}$ is the most probable proton relaxation time [18].

The M"/M"max curves are asymmetric, in agreement with the non - exponential behavior of the electrical function, which is well described by the empirical stretched exponential Kohlrausch function $\varphi(t)=\exp \left[-\left(\mathrm{t} / \tau_{\sigma}\right)^{\beta}\right](6)$ where $\beta$ $(0<\beta<1)$ is the stretched exponential parameter, [19-21]. The full width at half-maximum (FWHM) of the M"/M"max 
spectrum is greater than the breadth of a Debye - peak (1.14 decades) [22] and it results with an average value of $\beta=$ 0.84 for the Kohlrausch parameter. This value of $\beta$ clearly indicates that the relaxation is non-exponential.

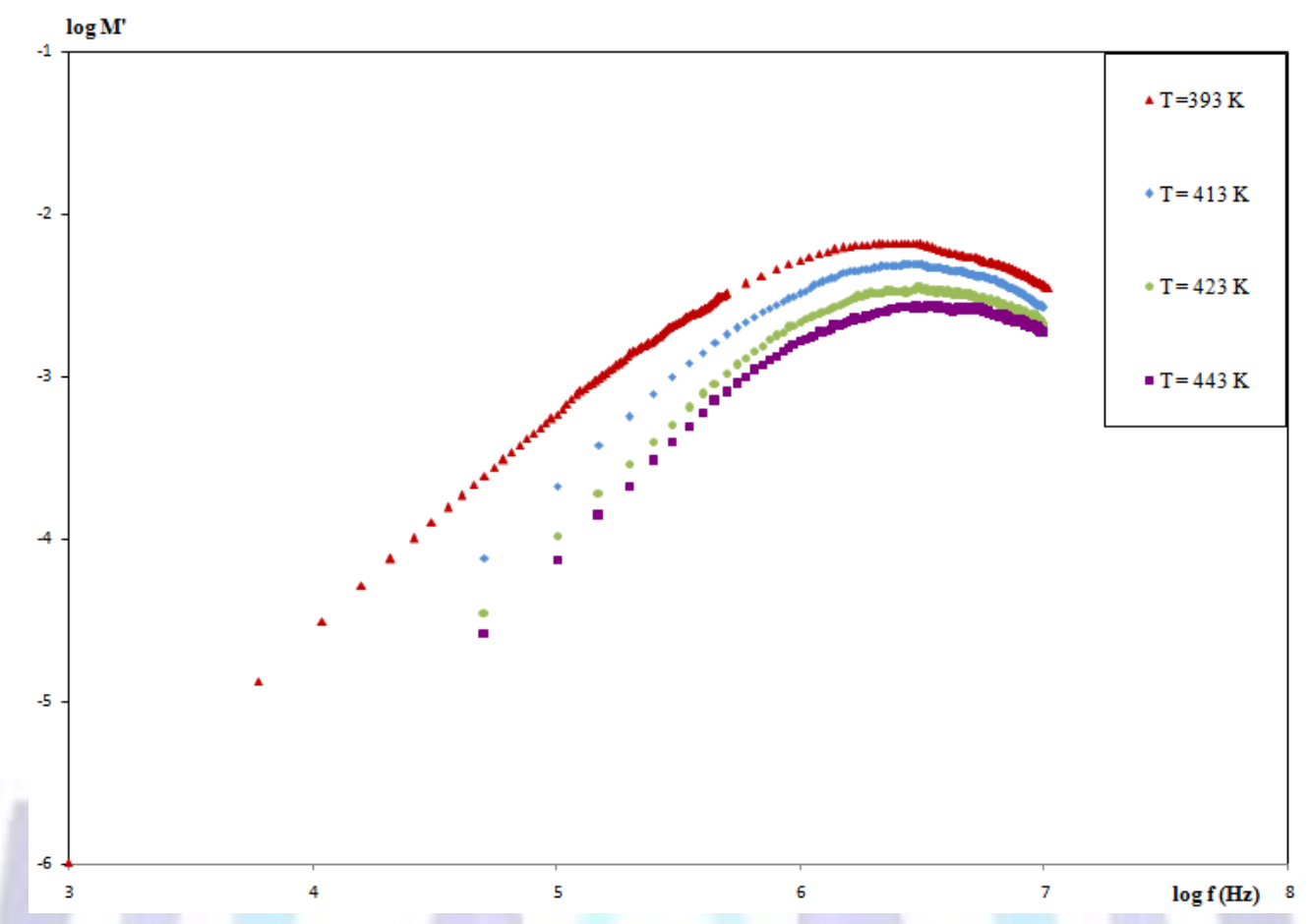

Figure 6: Plots of log $\mathrm{M}^{\prime}$ versus log f for $\mathrm{Rb}_{2}\left(\mathrm{HSeO}_{4}\right)_{1.5}\left(\mathrm{H}_{2} \mathrm{AsO}_{4}\right)_{0.5}$ at various temperatures

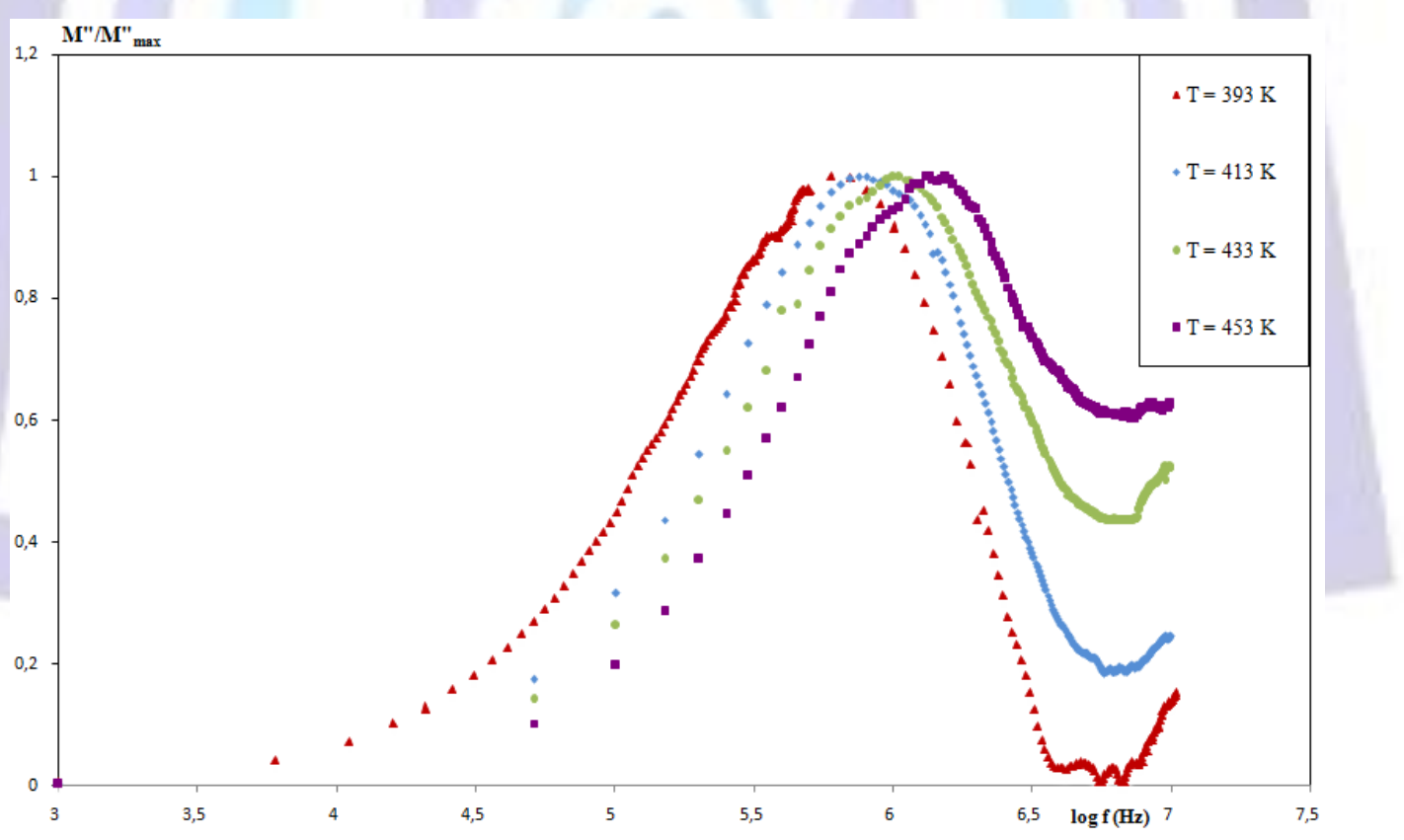

Figure 7: Plots of normalized modulus (M"/M"max) versus log f for $\mathrm{Rb}_{2}\left(\mathrm{HSeO}_{4}\right)_{1.5}\left(\mathrm{H}_{2} \mathrm{AsO}_{4}\right)_{0.5}$ compound at various temperatures

In Fig. 5, we introduce the temperature dependence of $\log (f p)$, where $f_{p}=1 / 2 \pi \tau_{\sigma}$ (7) is the frequency relative to M"max peak corresponding to the bulk relaxation. For all given temperatures, an Arrhenius - type law is shown with a noticeable break observed at about $443 \mathrm{~K}$. Above this temperature the activation energy value is $0.29 \mathrm{eV}$. This result confirms the presence of the superprotonic transition already observed by measurements of conductivity, D.S.C. and T.G.A. approximately at the same temperature. At low and high temperatures, both lines of the conductivity log $(\sigma \mathrm{T})$ and the modulus peak maxima log (fp) observed in the temperature studied are quasi - parallel, the activation energies 
deduced from the impedance $\left(\Delta \mathrm{E}_{\sigma}\right)$ and modulus $\left(\Delta \mathrm{E}_{\mathrm{f}}\right)$ spectra are very close $\left(\Delta \mathrm{E}_{\sigma(\mathrm{IIT})}=0.54 \mathrm{eV} ; \Delta \mathrm{E}_{\mathrm{f}(\mathrm{IIT})}=0.55 \mathrm{eV}\right)$, suggesting that the $\mathrm{H}^{+}$protons transport in (RbHSeAs) is probably due to a hopping mechanism [23].

On the other hand, the value of the full width at half-maximum (FWHM) of peaks (Fig. 7) corresponding to various temperatures is approximately close to an average value of 1.35 decades. Consequently, $\beta$ may be considered as independent of temperature in the studied temperature range. The value of the $\beta$ parameter, smaller than 1 , can be attributed to the existence of a distribution of relaxation times in the compound. Such an interpretation has been adopted for many solid electrolytes [24, 25]. On the contrary, recent studies based on the overlapping of the log $M$ ' vs log $f$ and log M" vs log f plots obtained for various temperatures have shown that this interpretation was questionable [18, 26].

\subsection{Vibrational studies}

\subsubsection{Assignments of Raman bands at room temperature}

To gain more information on the superprotonic phase transition, we have undertaken a vibrational study using Raman scattering. The tentative assignments of the vibrations are based on a comparison of Raman spectra of (RbHSeAs) with other spectra known from the literature [3, 4, 27, 28].

Raman spectra of both internal and external modes of polycrystalline samples of $\mathrm{Rb}_{2}\left(\mathrm{HSeO}_{4}\right)_{1.5}\left(\mathrm{H}_{2} \mathrm{AsO}_{4}\right)_{0.5}$ were recorded at different temperatures 300,453 and $523 \mathrm{~K}$ (Figs $8(\mathrm{a}, \mathrm{b})$ ). This study was restricted to the $10-1200 \mathrm{~cm}^{-1}$ spectral region because it included the lattice vibrations and $\mathrm{u}(\mathrm{X}-\mathrm{OH})$ and $\mathrm{u}(\mathrm{X}-\mathrm{O})$ (where $\mathrm{X}=\mathrm{As}$, Se) stretching modes, which are the most sensitive to phase transition and crystal changes [29]. The observed Raman bands at selected temperatures and their assignments are given in Table 1. In the Raman spectrum, the weak peaks at low frequencies $\left(<80 \mathrm{~cm}^{-1}\right)$ are assigned to translational vibrations of the $\mathrm{Rb}^{+}, \mathrm{SeO}_{4}{ }^{2-}$ and $\mathrm{AsO}_{4}{ }^{3-}$ ions and those at $95,164 \mathrm{~cm}^{-1}$ involve respectively the deformations and elongations of the hydrogen bonds $\delta(O \ldots O)$ and $v(O \ldots O)$. The bands in the 282-304 $\mathrm{cm}^{-1}$ and $320-417 \mathrm{~cm}^{-1}$ range are assigned to symmetric and antisymmetric deformation vibration of the $\mathrm{XO}_{4}$ group respectively (where $X=A s, S e$ ), and those in the range $744-860 \mathrm{~cm}^{-1}$ and $924-933 \mathrm{~cm}^{-1}$ (Fig. 8) are assigned to symmetric and antisymmetric elongation vibration of the $\mathrm{XO}_{4}$ group respectively.

\subsubsection{Superprotonic phase transition}

The spectral evolution illustrated in Figs $8(a, b)$ characterizes clearly the superprotonic phase transition at about $\mathrm{T}=453 \mathrm{~K}$. Its transition temperature is close to that found by differential scanning calorimetry, X-ray powder diffraction and conductivity measurements. This transition is characterized by spectral changes in the spectral regions studied. Thus, the following changes are noted: (1) Both the internal and external modes show progressive broadening (Figs $6(\mathrm{a}, \mathrm{b})$ ). The large broadening of the external modes, namely that of $\mathrm{SeO}_{4}^{-2}$ and $\mathrm{AsO} 4^{-3}$ motions (T), indicates weakening of the hydrogen bonds and the occurrence of a libration of $\mathrm{H}(\mathrm{Se} / \mathrm{As}) \mathrm{O}_{4}^{-2}$. (2) The lines assigned to $v_{1}\left(\mathrm{XO}_{4}\right)$ stretching decrease strongly in intensity at $744 \mathrm{~cm}^{-1}$ and in width at half height at $810 \mathrm{~cm}^{-1}$.

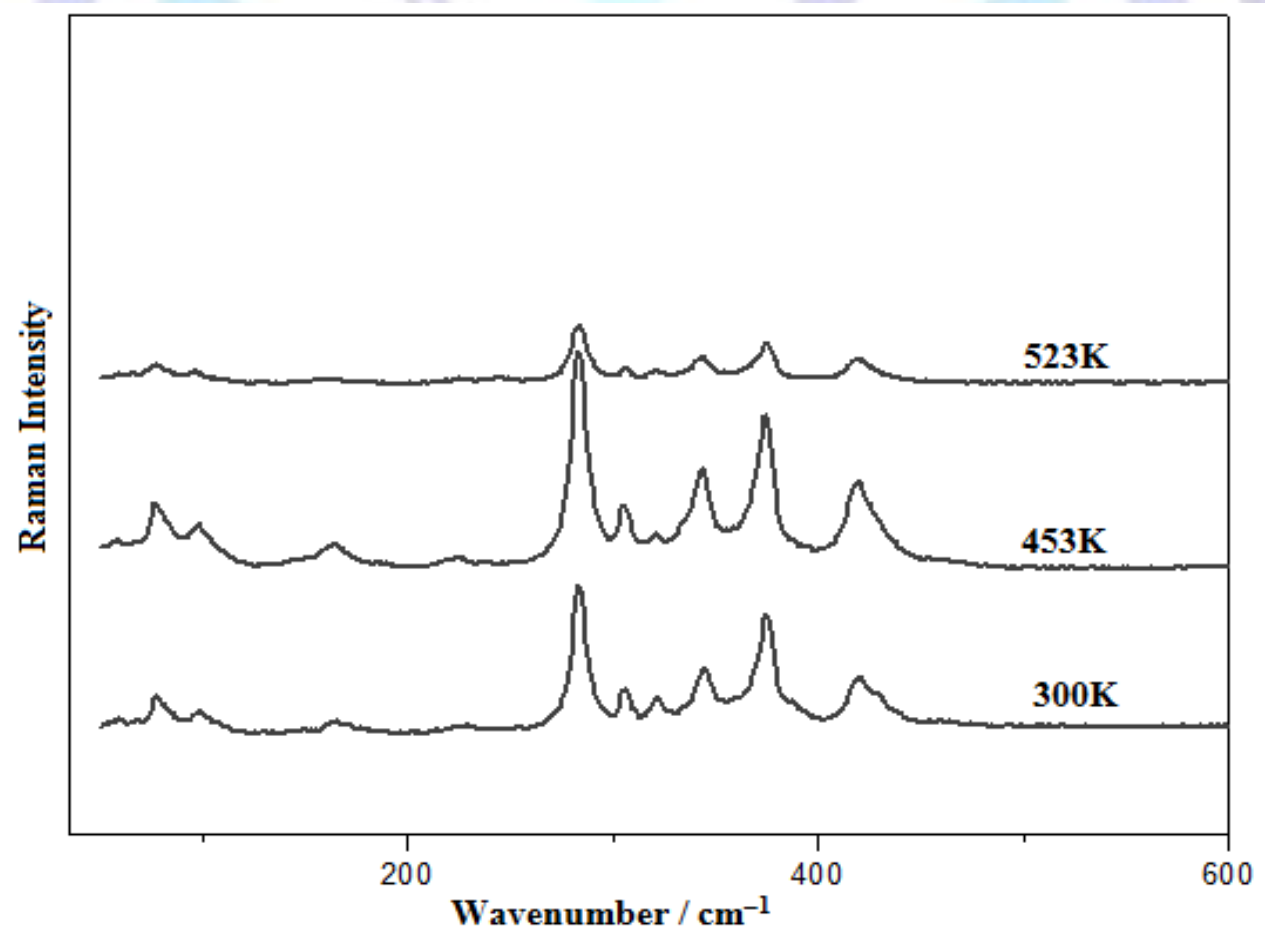

Figure 8(a): Raman spectra in the range $10-600 \mathrm{~cm}^{-1}$ for $\left.\mathrm{Rb}_{2}\left(\mathrm{HSeO}_{4}\right)_{1.5}\left(\mathrm{H}_{2} \mathrm{AsO}\right)_{4}\right)_{0.5}$ at various temperatures 
Table1: Raman bands and their assignments of $\mathrm{Rb}_{2}\left(\mathrm{HSeO}_{4}\right)_{1.5}\left(\mathrm{H}_{2} \mathrm{AsO}_{4}\right)_{0.5}$ at selected temperatures

\begin{tabular}{|c|c|c|c|}
\hline $\begin{array}{l}\mathrm{T}=300 \mathrm{~K} \\
\text { Raman }\left(\mathrm{cm}^{-1}\right)\end{array}$ & $\begin{array}{l}\mathrm{T}=453 \mathrm{~K} \\
\operatorname{Raman}\left(\mathrm{cm}^{-1}\right)\end{array}$ & $\begin{array}{l}\mathrm{T}=523 \mathrm{~K} \\
\operatorname{Raman}\left(\mathrm{cm}^{-1}\right)\end{array}$ & Assignment \\
\hline 61 & 60 & - & Lattice vibrations of \\
\hline 77 & 75 & 74 & $\mathrm{Rb}^{+}, \mathrm{SeO}_{4}{ }^{2-}$ and $\mathrm{AsO}_{4}{ }^{3-}$ \\
\hline 95 & 96 & 95 & $\delta_{0 \cdots O}$ \\
\hline 164 & 165 & - & $v_{0} \cdots O$ \\
\hline 282 & 284 & 283 & $v_{2}\left(\mathrm{XO}_{4}\right)$ \\
\hline 304 & 304 & 305 & \\
\hline 320 & 320 & 321 & \\
\hline 342 & 341 & 346 & $v_{4}\left(\mathrm{XO}_{4}\right)$ \\
\hline 373 & 373 & 374 & \\
\hline 417 & 417 & 419 & \\
\hline 744 & 745 & 743 & \\
\hline 764 & 764 & 767 & \\
\hline 810 & 810 & 812 & $v_{1}\left(\mathrm{XO}_{4}\right)$ \\
\hline 860 & 857 & 857 & \\
\hline 924 & 924 & 923 & $v_{3}\left(\mathrm{XO}_{4}\right)$ \\
\hline 933 & 932 & - & \\
\hline
\end{tabular}

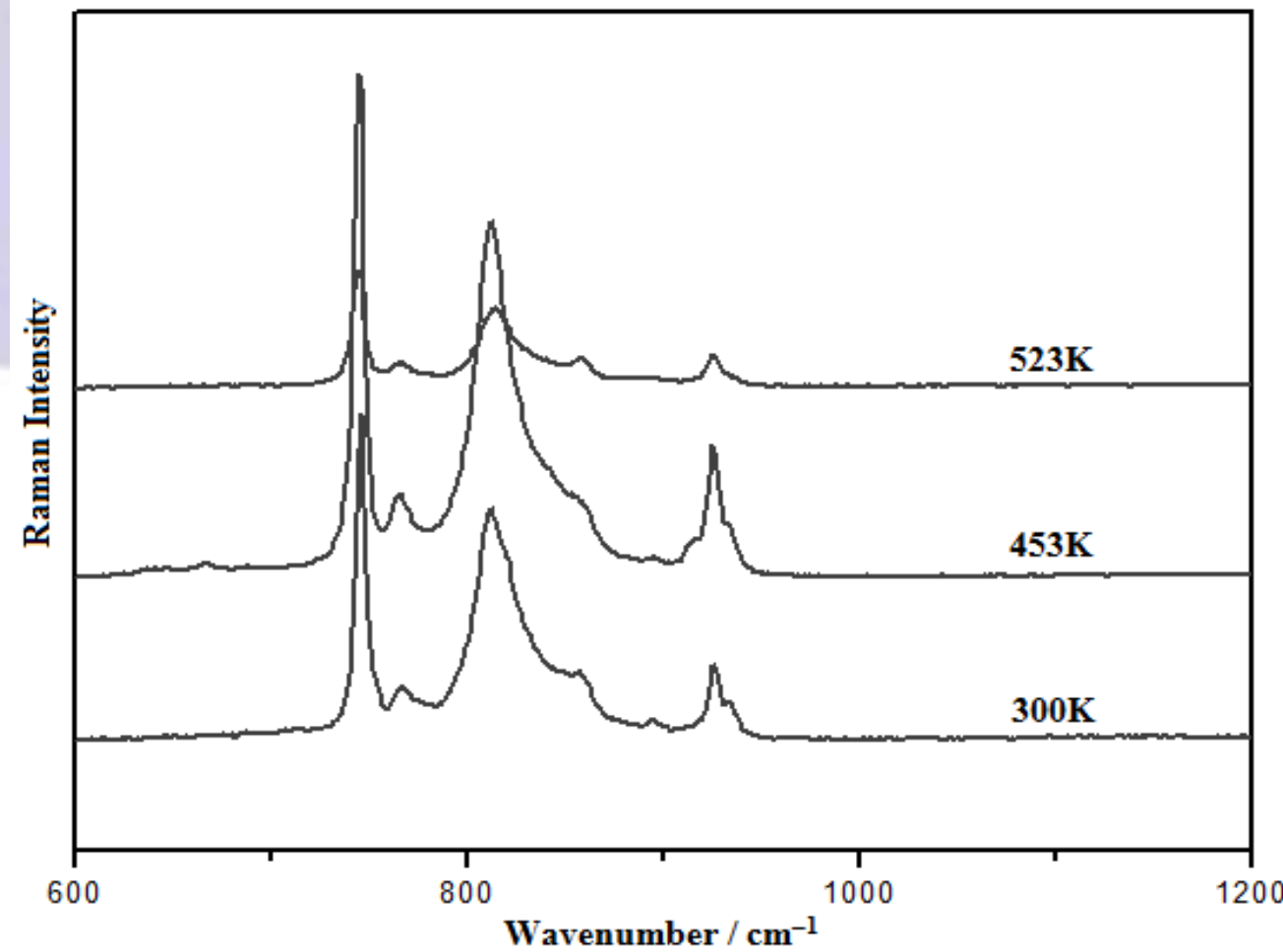

Figure 8(b): Raman spectra in the range $600-1200 \mathrm{~cm}^{-1}$ for $\mathrm{Rb}_{2}\left(\mathrm{HSeO}_{4}\right)_{1.5}\left(\mathrm{H}_{2} \mathrm{As} \mathrm{O}_{4}\right)_{0.5}$ at various temperatures 


\section{CONCLUSION}

The physical properties and phase transitions of the $\mathrm{Rb}_{2}\left(\mathrm{HSeO}_{4}\right)_{1.5}\left(\mathrm{H}_{2} \mathrm{AsO}_{4}\right)_{0.5}$ compound were examined by different methods. The differential scanning calorimetry and thermo-gravimetric analyses (D.S.C-T.G.A.) showed that (RbHSeAs) undergoes structural changes over the temperature $465 \mathrm{~K}$ which is unrelated to decomposition; its weight showed by the thermo-gravimetric curve (T.G.A) is stable to $~ 480 \mathrm{~K}$. This endothermic peak was also characterized by $\mathrm{X}$-ray powder diffraction verses temperature and was attributed to the superprotonic phase transition of (RbHSeAs). The decomposition of $\mathrm{Rb}_{2}\left(\mathrm{HSeO}_{4}\right)_{1.5}\left(\mathrm{H}_{2} \mathrm{AsO}_{4}\right)_{0.5}$ occurs in two stages. Approximately $5 \%$ of the mass is lost, which corresponds to 1.25 molecules of water per formula unit or complete dehydration. The weight loss is accompanied by one endothermic peak in the DSC curve at $566 \mathrm{~K}$.

The analysis of the ac conductivity data and the modulus formalism support these results. From ac impedance measurements, both conductivity and modulus spectra of this compound were analysed at low and high frequencies in the $403-483 \mathrm{~K}$ temperature range. The relaxation conductivity is well described by the empirical, stretched exponential Kohlrausch function $\varphi(t)=\exp \left[-\left(\mathrm{t} / \tau_{\sigma}\right)^{\beta}\right]$. The value of the $\beta$ parameter $(0<\beta<1)$ represents for the conductivity relaxation the departure from the simple exponential $(\beta=1)$. The $f_{p}$ frequency relative to $M^{\prime \prime}{ }_{\max }\left(f_{p}=1 / 2 \pi \tau_{\sigma}\right)$ is defined by the condition $\omega \tau_{\sigma}=1$, where $\tau_{\sigma}$ is the most probable ion relaxation time. $f_{p}$ increases with increasing temperature and the temperature dependence of $f_{p}$ is of Arrhenius type $\left(f_{p}=f_{p}{ }^{0} \exp \left(-\Delta E_{f} / k T\right)\right.$. Information about the charge carrier transport mechanism was obtained by comparison of $\Delta \mathrm{E}_{f}$ with $\Delta \mathrm{E}_{\sigma}$. Below $443 \mathrm{~K}$, the activation energies for the (RbHSeAs) compound calculated from the modulus and impedance spectra respectively, are approximately equal, suggesting that the protonic transport is probably due to a hopping mechanism. On the other hand, in the temperature range studied, $\beta$ may be considered as independent of temperature. The value of this parameter, smaller than 1 , shows the existence of a distribution of relaxation times in the (RbHSeAs) compound and confirms the validity of this model for proton conductivity.

The evolution of the Raman spectrum as a function of temperature characterizes clearly the transition superprotonic phase about $\mathrm{T}=453 \mathrm{~K}$. Its transition temperature is close to that found by differential scanning calorimetry, X-ray diffraction powder and conductivity measurements.

\section{REFERENCES}

[1] K. Jaouadi, N. Zouari, T. Mhiri, M. Giorgi, journal of Phase Transition, 78 (2005) 627.

[2] K. Jaouadi, N Zouari, T. Mhiri, A. Daoud, M. Jannin, journal of Alloys and Compounds, 413 (2006) 46.

[3] N Zouari, K. Jaouadi, T. Mhiri, journal of Solid Stat lonics, 177 (2006) 237.

[4] K. Jaouadi, N. Zouari, T. Mhiri, M. Giorgi, journal of Physics Procedia, 2 (2009) 1185.

[5] CRI. Chisholm, SM. Haile, Acta Cryustallographica, B55 (1999) 937.

[6] CRI. Chisholm, SM. Haile, journal of Solid Stat Ionics, 136-137 (2000) 229.

[7] A.I. Baranov, A.V. Tregubchenko, L.A. Shuvalov, N.M. Shechagina, Sov. Phys. Solid State, 29 (1987) 1448.

[8] M. Boubia, M. T. Averbuch-Pouchot et A. Durif, Acta crystallographica, C41 (1985) 1562.

[9] KD. Kreuer, journal of Mater Chemistry, 8 (1996) 610.

[10] B. Zhu, I. Albirson G. Mong, journal of Solid State lonics, 125 (1999) 439.

[11] B. Zhu, journal of Solid State lonics, 125 (1999) 397.

[12] R. Brouchet, S. Miller, M. Duclot, journal of Solid State lonics, 145 (2001) 69.

[13] K. Jaouadi, M. Amri, N. Zouari, T. Mhiri, S. Pechev, journal of Materials Research Bulletin, Submitted (2014).

[14] W. Rekik , H. Naili, T. Mhiri, journal of Organometallic Chemistry 691 (2006) 4725

[15] P. Colomban, Proton Conductors: Solids, Membranes, and Gels Materials and Devices; Chemistry of Solid State Materials, Cambridge University Press, (1992).

[16] N.G. Hainovsky, E. Hairetdinov, Izv. Ot. SSSR Ser, Khim. Nauk, 8 (1986) 33.

[17] A. Novak, Structure Bonding 18 (1974) 177.

[18] H. K. Patel, S. W. Martin, Phys. Rev. B 45 (1992) 10292.

[19] F. S. Howell, R. A. Bose, P. B. Macedo, C. T. Moynihan, journal of Phys. Chem. 78 (1974) 639.

[20] G. Williams, D. C. Watts, Trans. Faraday Soc. 23 (1970) 625.

[21] K. L. Ngai, S. W. Martin, Phys. Rev. B 40 (1989) 10550.

[22] S. W. Martin, C. A. Angell, journal Cryst. Solids 83 (1986) 185.

[23] B. V. R. Chowdari, R. Gopalakrishnan, journal of Solid State lonics 23 (1987) 225.

[24] J. Kawamura, M. Shimoji, journal of Mat. Chem. Phys. 23 (1989) 99. 
[25] C. Liu, H. G. K. Sundar, C. A. Angell, journal of Solid State lonics, 18 (1986) 442.

[26] S. W. Martin, Appl. Phys., A 49 (1989) 239.

[27] M. Amri, K. Jaouadi, N. Zouari, T. Mhiri, F. Mauvy, S. Pechev, P. Gravereau, journal of Physics and Chemistry of Solids, 74 (2013) 737.

[28] W. Hayes, H. Loudon, Scattering of Light by Crystals, John Wiley and Sons (1978).

[29] K. Jaouadi, N. Zouari, T. Mhiri, A. Daoud, F. Romain, journal of Raman Spectrosc, 38 (2007) 344. 